\title{
ASPECTOS DA PRODUTIVIDADE DO FEIJÃO CORRELACIONADOS COM ATRIBUTOS FÍSICOS DO SOLO SOB ELEVADO NÍVEL TECNOLÓGICO DE MANEJO(1)
}

\author{
Rafael Montanari ${ }^{(2)}$, Morel de Passos e Carvalho ${ }^{(3)}$, Marcelo \\ Andreotti $^{(4)}$, Flávio Carlos Dalchiavon ${ }^{(5)}$, Lenon Henrique Lovera ${ }^{(6)} \&$ \\ Max Alexandre de Oliveira Honorato ${ }^{(6)}$
}

\begin{abstract}
RESUMO
No ano agrícola de 2006/07, no município de Selvíria (MS), foi analisada a produtividade do feijão em função de alguns atributos físicos de um Latossolo Vermelho distroférrico, cultivado nas condições de elevado nível tecnológico de manejo pelo sistema plantio direto irrigado com pivô central. O objetivo foi selecionar, entre os atributos pesquisados do solo, aquele com a melhor representatividade para explicar a variabilidade da produtividade agrícola. Foi instalada a malha geoestatística, para a coleta de dados do solo e da planta, com 117 pontos amostrais, numa área de $2.025 \mathrm{~m}^{2}$ e declive homogêneo de $0,055 \mathrm{~m} \mathrm{~m}^{-1}$. Do ponto de vista linear e espacial, a produtividade de feijão foi explicada em função da densidade de partículas e da umidade gravimétrica do solo, respectivamente. Assim, os valores de densidade de partículas entre 1,95 e $2,20 \mathrm{~kg} \mathrm{dm}^{-3}$ e de umidade gravimétrica entre 0,205 e $0,239 \mathrm{~kg} \mathrm{~kg}^{-1}$, ambas coletadas na camada intermediária, resultaram em sítios com as mais elevadas produtividades $\left(2.200-2.600 \mathrm{~kg} \mathrm{ha}^{-1}\right)$. Entretanto, para as condições do elevado nível tecnológico de manejo empregado, a produtividade média do feijão não atingiu seu máximo potencial, uma vez que o agravado estado de compactação no qual o solo se encontrava proporcionou à
\end{abstract}

\footnotetext{
(1) Parte da Tese de Doutorado do primeiro autor - Programa de Pós-Graduação em Sistemas de Produção - Faculdade de Engenharia - UNESP/Campus de Ilha Solteira. Recebido para publicação em abril de 2009 e aprovado em outubro de 2010.

(2) Professor Adjunto da Universidade Estadual de Mato Grosso Do Sul - UEMS. Rodovia Aquidauana, km 12, CEP 79200-000 Aquidauana (MS). E-mail: rafamontana@uems.br

(3) Professor Livre-Docente do Departamento de Fitossanidade, Engenharia Rural e Solos, Faculdade de Engenharia - UNESP/ Campus de Ilha Solteira. Caixa Postal 31, CEP 15385-000 Ilha Solteira (SP). E-mail: morel@agr.feis.unesp.br

(4) Departamento de Fitossanidade, Engenharia Rural d Solos, Faculdade de Engenharia, Universidade Estadual Paulista UNESP. Av. Brasil 56, Centro, 15385-000, Ilha Solteira (SP). E-mail: dreotti@agr.feis.unesp.br

(5) Aluno de Mestrado, Departamento de Fitossanidade, Engenharia Rural e Solos, Faculdade de Engenharia, UNESP. E-mail: fcdalchiavon@hotmail.com

(6) Alunos do Curso de Graduação em Agronomia, UEMS. E-mails: lenon_lovera@hotmail.com; alexandre_honorato51@hotmail.com
} 
produtividade redução de 26,6 \% . Dessa forma, os valores médios da densidade do solo e da resistência do solo à penetração, respectivamente nas faixas de 1,36$1,41 \mathrm{~kg} \mathrm{dm}^{-3}$ e de 1,56-3,24 MPa, típicos de solos argilosos compactados, atestaram a substancial queda da produtividade de grãos de feijão.

Termos de indexação: manejo do solo, sistema plantio direto, qualidade física do solo, sustentabilidade agrícola, Phaseolus vulgaris.

\title{
SUMMARY: ASPECTS OF COMMON BEAN YIELD WITH A HIGH TECHNOLOGICAL MANAGEMENT LEVEL AS CORRELATED WITH SOIL PHYSICAL PROPERTIES
}

\begin{abstract}
Common bean yield was analyzed in relation to some physical properties of a dystroferric Red Latosol (Typic Acrustox), in the 2006/07 growing season, in Selviria, state of Mato Grosso do Sul, Brazil. The no-tillage crop under center-pivot irrigation was cultivated with a high technological management level. The objective of this work was to select the most representative soil properties to explain the variability in agricultural productivity. A geostatistical grid was installed for soil and plant sampling at 117 points, in a 2,025 $\mathrm{m}^{2}$ area with a homogeneous slope of $0.055 \mathrm{~m} \mathrm{~m}^{-1}$. From the linear and spatial point of view, common bean yield was explained by particle density and soil gravimetric moisture, respectively. Thus, at values of particle density between $1.95-2.20 \mathrm{~kg} \mathrm{dm}^{-3}$ and gravimetric moisture between $0.205-$ $0.239 \mathrm{~kg} \mathrm{~kg}^{-1}$, both measured in the intermediary layer, highest yields $\left(2,200-2,600 \mathrm{~kg} \mathrm{ha}^{-1}\right)$ were observed. However, at the high technological management level used in this study, the maximum potential of the mean common bean yield was not reached, since the soil was severely compacted, leading to a decrease of $26.6 \%$. The mean values of bulk density and the soil index cone, of $1.36-1.41 \mathrm{~kg} \mathrm{dm}^{-3}$ and 1.56-3.24 MPa, respectively, typical of compacted clay soils, accounted for the marked decrease in common bean yield.
\end{abstract}

Index terms: soil management, no-tillage system, soil physical quality, agricultural sustainability, Phaseolus vulgaris.

\section{INTRODUÇÃO}

No Brasil, a cultura do feijoeiro (Phaseolus vulgaris L.) constitui-se numa das mais representativas explorações agrícolas, não só pela área de cultivo, como também pelo valor da produção. Trata-se de um componente importante na alimentação básica da população nacional, por ser rico em proteínas e ferro. Quanto à disposição do sistema radicular no solo, ele se assemelha ao fasciculado, uma vez que a raiz primária não é uma pivotante típica, além de sua grande maioria situar-se nos primeiros $0,20 \mathrm{~m}$ de profundidade, sendo de $62-87 \%$ nos primeiros $0,10 \mathrm{~m}$ (Freddi et al., 2005). Em consequência, a planta explora essencialmente a sua camada superficial, sendo, portanto, muito sensível à falta de umidade e à compactação (Vieira et al., 2006). Na safra 2006/2007, sua produção chegou a 3,339 milhões de toneladas, ocupando uma área de aproximadamente 4,087 milhões de hectares, com destaque para as regiões Sul, Sudeste e Nordeste, que produziram 1.150, 839 e 801 mil toneladas de grãos, respectivamente, com produtividade média de $817 \mathrm{~kg} \mathrm{ha}^{-1}$ (CONAB, 2008; Martins et al., 2009). Ainda em relação à referida produtividade, a literatura cita os seguintes números: (a) $1.000-3.000 \mathrm{~kg} \mathrm{ha}^{-1}$, para o feijão irrigado no Estado de São Paulo (Fahl et al., 1998); e (b) 1.239 e $1.895 \mathrm{~kg} \mathrm{ha}^{-1}$, respectivamente para os Estados de São Paulo e Goiás, assim como a quantidade de $3.000 \mathrm{~kg} \mathrm{ha}^{-1}$, quando empregado elevadíssimo nível tecnológico (Vieira et al., 2006).

Os solos do Estado de Mato Grosso do Sul tem passado por grandes problemas de degradação física e química devido ao intensivo uso, à erosão, à perda da fertilidade, à redução do conteúdo de matéria orgânica e, principalmente, à formação de camadas compactadas. Essa compactação gera substancial alteração da sua estrutura, desencadeando a reorganização das partículas e de seus agregados, podendo limitar a absorção de nutrientes, a infiltração e redistribuição de água, as trocas gasosas e o crescimento do sistema radicular, resultando no decréscimo da produtividade das culturas (Roque et al., 2008).

Normalmente, após uma década de utilização do sistema plantio direto, por estar ele associado ao intenso tráfego de máquinas agrícolas e ao não revolvimento da leiva, observa-se a compactação da 
camada superficial do solo, principalmente nos primeiros $0,17 \mathrm{~m}$. Contudo, trata-se de um sistema conservacionista (Vieira et al., 2006), que mantém os resíduos vegetais dos cultivos anteriores na superfície, assim como uma mínima taxa de erosão $\left(5,5 \mathrm{t} \mathrm{ha}^{-1}\right.$ ano, equivalente à tolerância de perda por erosão de 12,0-15,0 t ha-1 ano) (IAPAR, 1981; Bertoni \& Lombardi Neto, 1990), apresentando-se como uma alternativa para contribuir com a sustentabilidade econômica e ambiental desse agroecossistema (Carneiro et al., 2009).

A densidade do solo (DS) e a resistência do solo à penetração $(\mathrm{RP})$ são os atributos mais utilizados para avaliar a compactação do solo, tendo a segunda estreita correlação com o crescimento radicular. Assim, os Latossolos Vermelhos distroférricos e eutroférricos, em condições naturais e com a mínima intervenção antrópica, apresentam na superfície $(0-0,30 \mathrm{~m})$ valores de densidade do solo entre 0,98 e $1,13 \mathrm{~kg} \mathrm{dm}^{-3}$ (Oliveira \& Moniz, 1975) e de RP em torno de $1,32 \mathrm{MPa}$ (Carneiro et al., 2009). Por sua vez, Arshad et al. (1996) relataram que valores de resistência à penetração maiores que $2,00 \mathrm{MPa}$ restringiram o desenvolvimento radicular das culturas agrícolas em geral. Já para Carvalho et al. (2006), quando variaram entre 1,29 e 2,87 MPa, esses valores não restringiram a produtividade de grãos da cultura do feijão. Entretanto, conforme Bengough et al. (2001), visando atestar a correta interpretação final dessa resistência, também é conveniente, na ocasião da amostragem, coletar concomitantemente os dados de densidade do solo e de umidade atual, uma vez que, em relação a eles, a $\mathrm{RP}$ varia de forma direta e inversamente proporcional, respectivamente

Camargo \& Alleoni (1997), no ensaio sobre compactação e desenvolvimento das plantas em um solo argiloso, relataram que o valor da densidade do solo de $1,55 \mathrm{~kg} \mathrm{dm}^{-3}$ torna limitante o desenvolvimento vegetativo. Esse valor, assim como sua influência sobre o desenvolvimento das culturas, além de estar intimamente associado aos atributos intrínsecos do solo, como textura e estrutura, também é dependente do cultivo e do manejo do solo.

A densidade de partícula sólida do solo - também conhecida apenas como densidade de partículas - é dada pela razão entre a massa de uma amostra deformada de solo, seca a $110^{\circ} \mathrm{C}$, e o seu volume de sólidos, sem considerar a porosidade, quantificada em $\mathrm{kg} \mathrm{dm}^{-3}$. Trata-se de um atributo muito pouco utilizado na pesquisa de manejo do solo, devido ao seu caráter imutável diante da ação antrópica que o preparo do solo desencadeia (Camargo \& Alleoni, 1997).

A análise geoestatística da variabilidade do solo pode indicar alternativas de manejo, não só para reduzir os efeitos da variabilidade dos atributos do solo sobre a produção agrícola, como também para aumentar sua resposta às diversas práticas culturais empregadas (Trangmar et al., 1985). Dessa forma, a coleta espacial dos valores de um determinado atributo pode revelar grandes variações porque, sendo o solo um produto da ação de diversos fatores de formação, varia muito nas suas três dimensões, sobretudo na superfície (Roque et al., 2008).

Conforme os preceitos da estatística clássica, normalmente, ao se analisarem os atributos do solo, as consequências da heterogeneidade espacial sobre a representatividade dos valores médios são ignoradas. No entanto, o método geoestatístico, além de analisar a dependência espacial desses valores, ainda proporciona meios para que sejam efetuados os respectivos mapeamentos, por meio da krigagem e, ou, da cokrigagem. Assim, a extensão multivariada da krigagem, conhecida como cokrigagem, é utilizada quando entre dois atributos quaisquer, do solo e, ou, planta, ocorrer dependência espacial tanto para cada um deles como entre eles. Além disso, exclusivamente em relação à variável primária, que normalmente é subamostrada, essa técnica possibilita efetuar a estimativa dos seus valores não amostrados. A cokrigagem pode ser mais precisa do que a krigagem de um atributo simples quando o semivariograma cruzado apresentar dependência entre dois atributos quaisquer (Trangmar et al., 1985). Portanto, conforme preceitos de Coelho (2003), esse procedimento permite determinar se um atributo apresenta ou não estrutura espacial, e, uma vez conhecido o modelo da dependência espacial, é possível mapear a área estudada. Dessa forma, são estabelecidas as zonas específicas de manejo que são fundamentais à aplicação de insumos com taxas variadas - condições necessárias à agricultura de precisão.

Com o surgimento da agricultura de precisão, ultimamente no Brasil o estudo geoestatístico dos atributos físicos do solo com a produtividade do feijão vem se intensificando (Freddi et al., 2005; Santos et al., 2005; Carvalho et al., 2006; Kitamura et al., 2007; Roque et al., 2008; Martins et al., 2009). Assim, em relação à produtividade de feijão, densidade de partículas, densidade do solo, RP e umidade gravimétrica, os alcances da dependência espacial observados pelos referidos autores variaram entre: (a) 6,1 e 29,8 m, para a produtividade do feijão; (b) efeito pepita puro, para a densidade de partículas; c) 29,9 e $39,8 \mathrm{~m}$, para a densidade do solo; (d) 2,2 e $67,1 \mathrm{~m}$, para a RP; e (e) 11,8 e $65,8 \mathrm{~m}$, para a umidade gravimétrica. Por outro lado, Martins et al. (2009) observaram significativa cokrigagem entre a produtividade de feijão com a densidade do solo e a umidade volumétrica, com coeficiente de determinação espacial $\left(r^{2}\right)$ entre 0,665 e 0,734 .

Diante do exposto, tendo a cultura do feijão estabelecida em Selvíria (MS), nas condições de elevado nível tecnológico de manejo, o presente trabalho objetivou pesquisar, entre os atributos físicos estudados do solo sob plantio direto, aqueles que melhor expliquem, linear e espacialmente, a variabilidade da produtividade de grãos de feijão. 


\section{MATERIAL E MÉTODOS}

O experimento foi realizado na Fazenda de Ensino e Pesquisa - Setor de Produção Vegetal, da Faculdade de Engenharia de Ilha Solteira (FE/UNESP), localizada no município de Selvíria (MS), entre as latitudes de $20^{\circ} 18^{\prime} 05^{\prime} \mathrm{S}$ e $20^{\circ} 18^{\prime} 28^{\prime} \mathrm{S}$ e as longitudes de $52^{\circ} 39^{\prime} 02$ " W e $52^{\circ} 40$ ' $28^{\prime}$ " W. Sua precipitação média anual é de $1.300 \mathrm{~mm}$, enquanto a temperatura média é de $23,7^{\circ} \mathrm{C}$. O tipo climático é Aw, segundo Köppen, caracterizado como tropical úmido com estação chuvosa no verão e seca no inverno. O solo no qual a malha experimental foi instalada é um Latossolo Vermelho distroférrico típico muito argiloso, A moderado, hiperdistrófico, álico, caulinítico, férrico, muito profundo, moderadamente ácido (Typic Acrustox), com declividade homogênea de $0,055 \mathrm{~m} \mathrm{~m}^{-1}$ (Embrapa, 2006). Sua granulometria, analisada da superfície até $0,30 \mathrm{~m}$, é de $620 \mathrm{~g} \mathrm{~kg}^{-1}$ de argila, $100 \mathrm{~g} \mathrm{~kg}^{-1}$ de silte, $60 \mathrm{~g} \mathrm{~kg}^{-1}$ de areia grossa e $220 \mathrm{~g} \mathrm{~kg}^{-1}$ de areia fina, o que lhe confere a textura muito argilosa. Ele vem sendo cultivado há pelo menos 20 anos com a sucessão de culturas do milho e do feijão, semeadas no verão e inverno, respectivamente. Nos anos de 1998 e 2003, nas duas estações, o solo foi preparado com o arado de aivecas; nos demais, pelo sistema plantio direto irrigado sob pivô central.

A planta-teste pesquisada foi o feijão (Phaseolus vulgaris L.), semeado em 6/5/2006, após a dessecação das plantas daninhas com o herbicida glifosato, na dose de $1,8 \mathrm{~kg} \mathrm{ha}^{-1}$ do ingrediente ativo. O cultivar semeado foi o Pérola, cujo cultivo foi conduzido segundo as instruções agrícolas para as principais culturas agrícolas do Estado de São Paulo (FAHL et al., 1998) Dessa forma, o espaçamento entre linhas foi de $0,45 \mathrm{~m}$, com densidade final de 16 plantas por metro na linha de semeadura. Foram definidas as direções x e y do sistema de coordenadas cartesianas, num lançante estabelecido entre dois terraços agrícolas, no qual estava semeada a cultura estudada. Para isso, foi utilizado o nível ótico comum, efetuando-se o estaqueamento global da malha experimental, dentro do referido lançante, em 14/6/2006. Essa malha foi constituída de nove transeções com $40 \mathrm{~m}$ de comprimento, em ambas as direções dos eixos, numa área de $2.025 \mathrm{~m}^{2}$. As transeções foram espaçadas de $5,00 \mathrm{~m}$, com pontos amostrais na forma de 5,00 x 5,00 m, contendo 81 deles. Entretanto, também foram alocados, dentro da grande malha, pontos com espaçamentos menores do que os mencionados, com $1,67 \mathrm{~m}$ entre eles, visando detalhar o estudo da dependência espacial. Como nesse caso foram 36, o total de pontos amostrais da malha foi de 117 .

Todos os atributos pesquisados do solo e da planta foram individualmente coletados no entorno e o mais proximo do ponto amostral da malha experimental, sendo o feijão colhido no estádio fenológico entre R7 e R8.
Os atributos do solo foram: (a) densidade de partículas (DP), (b) densidade do solo (DS), (c) resistência do solo à penetração $(\mathrm{RP})$ e $(\mathrm{d})$ umidade gravimétrica (UG), coletados em 18/6/2006 em três profundidades: $0-0,10 ; 0,10-0,20$; e $0,20-0,30 \mathrm{~m}$. Foi avaliada a produtividade de grãos do feijoeiro (PRG), realizada em $14 / 8 / 2006$. Coletaram-se quatro linhas de semeadura $(1,80 \mathrm{~m})$, de forma a haver sempre duas de cada lado do ponto amostral. Como o comprimento no sentido das linhas também foi de 1,80 m, a área útil colhida foi de $3,24 \mathrm{~m}^{2}$. Portanto, a relação dos 13 atributos pesquisados foi a seguinte: PRG, DP1, DP2, DP3, DS1, DS2, DS3, RP1, RP2, RP3, UG1, UG2 e UG3.

As amostras de solo, originadas de monólitos com estruturas indeformadas, foram obtidas para a determinação da DS. Dessa forma, a densidade do solo foi determinada pelo método do anel volumétrico, enquanto a umidade gravimétrica foi determinada com balança analítica, com precisão de $+/-0,005 \mathrm{~g}$, e a densidade de partículas foi determinada pelo método do balão volumétrico $\left[\mathrm{kg} \mathrm{dm}^{-3}\right]$. Todas elas foram determinadas conforme Embrapa (1997).

Os dados da resistência do solo à penetração foram obtidos com o penetrômetro de impacto e calculados segundo a seguinte expressão contida em Souza et al. (2001):

$$
\mathrm{RP}=\{\{5,581+6,891 .\{[\mathrm{N} /(\mathrm{P}-\mathrm{A})] \cdot 10\}\} \cdot 0,0981
$$

em que RP é a resistência mecânica do solo à penetração [MPa]; N é o número de impactos efetuados com o martelo do penetrômetro para obtenção da leitura; e A e P são, respectivamente, as leituras antes e depois da realização dos impactos [cm]. Essas determinações foram processadas no Laboratório de Análises Físicas do Solo da Faculdade de Engenharia/ UNESP/Campus de Ilha Solteira.

Para cada atributo estudado, efetuou-se a análise descritiva clássica, com auxílio do software estatístico SAS (Schlotzhaver \& Littell, 1997), em que foram calculados a média, mediana, valores mínimos e máximos, desvio-padrão, coeficiente de variação, curtose, assimetria e distribuição de frequência. Posteriormente, realizou-se a identificação dos outliers, efetuando a substituição dos seus valores pelo valor médio dos circunvizinhos contidos na malha. Para testar a hipótese de normalidade, ou de lognormalidade, foi utilizada a estatística de Shapiro \& Wilk a $5 \%$. Também, foi montada a matriz de correlação, objetivando efetuar as correlações lineares simples para as combinações, duas a duas, entre todos os atributos estudados, assim como apresentar as análises de regressões para os pares de maior interesse. Assim, selecionaram-se aqueles de maior correlação linear e que, portanto, poderiam apresentar semivariograma cruzado e a consequente cokrigagem. Isoladamente para cada atributo, foi analisada sua dependência espacial, pelo cálculo do semivariograma simples. Contudo, para aqueles que apresentaram 
interdependência espacial, calcularam-se também seus semivariogramas cruzados, com base nos pressupostos de estacionaridade da hipótese intrínseca, pelo uso do pacote Gamma Design Software (GS+, 2004). Os ajustes dos semivariogramas simples e cruzados, em função de seus modelos, foram efetuados prioritariamente pela seleção inicial de: (a) menor soma dos quadrados dos desvios (RSS); (b) maior coeficiente de determinação $\left(\mathrm{r}^{2}\right)$; e (c) maior avaliador da dependência espacial (ADE). A decisão final do modelo que representou o ajuste foi realizada pela validação cruzada, assim como para a definição do tamanho da vizinhança que proporcionou a melhor malha de krigagem e, ou, cokrigagem, realizadas por meio da krigagem em blocos. Para cada atributo, foram relacionados o efeito pepita (Co), o alcance (Ao) e o patamar $(\mathrm{Co}+\mathrm{C})$. A análise do avaliador da dependência espacial (ADE) foi feita conforme a seguinte expressão (GS+, 2004):

$$
\mathrm{ADE}=[\mathrm{C} /(\mathrm{C}+\mathrm{Co})] \cdot 100
$$

em que ADE é o avaliador da dependência espacial; $\mathrm{C}$, a variância estrutural; e C + Co, o patamar. A interpretação proposta para o $\mathrm{ADE}$ foi a seguinte: $\mathrm{ADE}$ $\leq 25 \%$ indicou variável espacial fracamente dependente; $25 \%<\mathrm{ADE} \leq 75 \%$ indicou variável espacial moderadamente dependente; e ADE > $75 \%$ indicou variável espacial fortemente dependente. Por outro lado, sabe-se que a validação cruzada é uma ferramenta destinada a avaliar modelos alternativos de semivariogramas simples e cruzados, que efetuarão a krigagem e a cokrigagem, respectivamente. Na sua análise, cada ponto contido dentro do domínio espacial é removido individualmente, sendo seu valor estimado como se não existisse. Dessa forma, pode-se construir um gráfico de valores estimados versus observados para todos os pontos. O coeficiente de correlação $(r)$ entre esses valores reflete a eficiência do ajuste, dado pela técnica da soma dos quadrados dos desvios, representando a equação de regressão linear em questão. Um ajuste perfeito teria o coeficiente de regressão igual a 1 e a linha do melhor ajuste coincidiria com o modelo perfeito, isto é, com o coeficiente linear igual a zero e o angular igual a 1 (GS $\left.{ }^{+}, 2004\right)$. Assim, trabalhando-se na obtenção do número ideal de vizinhos, foram obtidos, por meio da interpolação, os mapas de krigagem e de cokrigagem, para análise da dependência e da interdependência espacial entre os atributos. Os componentes geoestatísticos determinados foram o semivariogramas simples, semivariograma cruzado, validação cruzada, krigagem e cokrigagem.

\section{RESULTADOS E DISCUSSÃO}

A variabilidade de um atributo pode ser classificada conforme a magnitude do seu coeficiente de variação (Freddi et al., 2006). A produtividade de grãos (PRG) apresentou alta variabilidade, com o coeficiente de variação de 21 \% (Quadro 1). Esse dado ficou análogo ao de Freddi et al. (2005), Kitamura et al. (2007) e Martins et al. (2009), uma vez que esses autores trabalharam basicamente nas mesmas condições que as do presente trabalho, isto é, quando analisaram um Latossolo Vermelho distroférrico sob plantio direto, encontrando também alta variabilidade (24\%) para a produtividade de grãos do feijão.

Em todas as profundidades do solo, a variabilidade da densidade do solo (DS) e de partículas (DP) foi baixa, com coeficientes de variação entre 4 e 8 \% (Quadro 1). Assim, os dados de densidade do solo concordaram com aqueles de Santos et al. (2006), Lima et al. (2007) e Martins et al. (2009), os quais, trabalhando também com um Latossolo Vermelho distroférrico sob plantio direto, constataram variabilidade entre 3 e $10 \%$. Já os dados de densidade de partículas concordaram com os de Eguchi et al. (2002), que encontraram coeficiente de variação de $3 \%$.

Em relação à resistência do solo à penetração $(\mathrm{RP})$, a variabilidade foi muito alta (46\%), alta (27\%) e média (19\%), da superfície para a subsuperfície (Quadro 1). Assim, a variabilidade muito alta da primeira camada ficou de acordo com aquela (37\%) de Souza et al. (2006), como também a média variabilidade da terceira concordou com o observado por Freddi et al. (2006), que encontraram o valor de $14 \%$. Provavelmente isso possa ter ocorrido devido ao tráfego desuniforme de máquinas na superfície, ocasionando variabilidade.

Quando uma variável estatística qualquer possuir distribuição de frequência do tipo normal, a medida de tendência central mais adequada para representála deve ser a média; em contrapartida, será representada pela mediana, ou pela média geométrica, caso seja do tipo lognormal (Rosa Filho et al., 2009). Portanto, a medida de tendência central que representará os atributos PRG, DP3, DS1, DS2, DS3, RP2, UG1, UG2 e UG3 deverá ser a média, em razão de eles terem apresentado distribuição de frequência do tipo normal, com coeficientes de assimetria positiva, entre 0,004 e 0,323, assim como negativa, entre -0,415 e -0,170. Já os coeficientes de curtose positiva ficaram entre 0,176 e 0,807 , e da negativa, entre -0,722 e-0,116. Contudo, e independentemente desses coeficientes, todos foram significativos a $5 \%$ pelo teste de normalidade de Shapiro e Wilk, uma vez que essa probabilidade variou entre 0,055 e 0,850 (Quadro 1). Dessa forma, a distribuição de frequência do tipo normal obtida para os referidos atributos, assim como as magnitudes dos coeficientes de assimetria e de curtose, ficaram, no geral, em concordância com dados análogos observados por Santos et al. (2005); Carvalho et al. (2006); Freddi et al. (2006); Santos et al. (2006); Souza et al. (2006); Roque et al. (2008) e Martins et al. (2009). Os atributos DP1 e RP3 apresentaram distribuição de frequência do tipo tendendo a lognormal, e o DP2 e o RP1, do tipo indeterminada. 
Quadro 1. Análise descritiva inicial da produtividade do feijão e de alguns atributos físicos de um Latossolo Vermelho distroférrico de Selvíria (MS)

\begin{tabular}{|c|c|c|c|c|c|c|c|c|c|c|}
\hline \multirow{3}{*}{ Atributo $^{(1)}$} & \multicolumn{10}{|c|}{ Medidas estatísticas descritivas } \\
\hline & \multirow{2}{*}{ Média } & \multirow{2}{*}{ Mediana } & \multicolumn{2}{|c|}{ Valor } & \multirow{2}{*}{$\begin{array}{l}\text { Desvio- } \\
\text { padrão }\end{array}$} & \multicolumn{3}{|c|}{ Coeficiente } & \multicolumn{2}{|c|}{ Probabilidade do teste ${ }^{(2)}$} \\
\hline & & & Mínimo & Máximo & & Variação & Curtose & Assimetria & $\operatorname{Pr}<w$ & DF \\
\hline & \multicolumn{10}{|c|}{ Atributo da planta } \\
\hline PRG $\left(\mathrm{kg} \mathrm{ha}^{-1}\right)$ & 2200,9 & 2206,9 & 1225,2 & 3390,0 & 464,7 & 21,1 & $-0,625$ & 0,020 & 0,217 & NO \\
\hline $\mathrm{DP} 1\left(\mathrm{~kg} \mathrm{dm}^{-3}\right)$ & 2,265 & 2,253 & 2,040 & $\begin{array}{l}\text { Atribu } \\
2,598\end{array}$ & $\begin{array}{c}\text { tos do solo } \\
0,131\end{array}$ & 5,8 & $-0,660$ & 0,306 & 0,046 & $\mathrm{TL}$ \\
\hline $\mathrm{DP} 2\left(\mathrm{~kg} \mathrm{dm}^{-3}\right)$ & 2,263 & 2,233 & 1,991 & 2,681 & 0,145 & 6,4 & - & - & - & IN \\
\hline DP3 $\left(\mathrm{kg} \mathrm{dm}^{-3}\right)$ & 2,229 & 2,215 & 1,839 & 2,647 & 0,131 & 5,9 & 0,807 & 0,323 & 0,119 & NO \\
\hline $\mathrm{DS} 1\left(\mathrm{~kg} \mathrm{dm}^{-3}\right)$ & 1,362 & 1,365 & 1,120 & 1,563 & 0,107 & 7,9 & $-0,722$ & $-0,170$ & 0,055 & $\mathrm{NO}$ \\
\hline $\mathrm{DS} 2\left(\mathrm{~kg} \mathrm{dm}^{-3}\right)$ & 1,413 & 1,413 & 1,233 & 1,563 & 0,067 & 4,8 & 0,176 & $-0,318$ & 0,237 & NO \\
\hline $\operatorname{DS} 3\left(\mathrm{~kg} \mathrm{dm}^{-3}\right)$ & 1,391 & 1,394 & 1,203 & 1,499 & 0,059 & 4,3 & 0,379 & $-0,573$ & 0,031 & $\mathrm{TN}$ \\
\hline RP1 (MPa) & 1,563 & 1,562 & 0,547 & 3,702 & 0,727 & 46,6 & - & - & - & IN \\
\hline $\mathrm{RP} 2(\mathrm{MPa})$ & 2,618 & 2,584 & 0,701 & 4,904 & 0,713 & 27,2 & 0,709 & 0,291 & 0,129 & NO \\
\hline RP3 (MPa) & 3,236 & 3,190 & 1,900 & 5,117 & 0,619 & 19,2 & 0,219 & 0,108 & 0,449 & TL \\
\hline UG1 $\left(\mathrm{kg} \mathrm{kg}^{-1}\right)$ & 0,208 & 0,210 & 0,139 & 0,282 & 0,029 & 13,9 & $-0,116$ & 0,004 & 0,850 & NO \\
\hline $\mathrm{UG} 2\left(\mathrm{~kg} \mathrm{~kg}^{-1}\right)$ & 0,211 & 0,213 & 0,137 & 0,281 & 0,027 & 13,1 & 0,318 & $-0,362$ & 0,094 & NO \\
\hline UG3 $\left(\mathrm{kg} \mathrm{kg}^{-1}\right)$ & 0,214 & 0,219 & 0,128 & 0,282 & 0,029 & 13,6 & 0,320 & $-0,415$ & 0,141 & NO \\
\hline
\end{tabular}

(1) PRG: produtividade de grãos do feijão; DP, DS, RP e UG, de 1 a 3, são respectivamente a densidade de partícula, densidade do solo, resistência à penetração e umidade gravimétrica, coletados nas camadas do solo. ${ }^{(2)} \mathrm{DF}$ : distribuição de frequência, sendo NO, TN, TL e IN respectivamente do tipo normal, tendendo a normal, tendendo a lognormal e indeterminada.

Tendo por base os estudos geoestatísticos que analisaram as correlações entre a produtividade média do feijão e os atributos do solo, em relação ao presente trabalho, a produtividade média obtida $\left(2.200,9 \mathrm{~kg} \mathrm{ha}^{-1}\right)$ (Quadro 1) foi 15,2\% menor do que a de Freddi et al. (2005), Kitamura et al. (2007) e Martins et al. (2009), que alcançou $2.594 \mathrm{~kg} \mathrm{ha}^{-1}$; contudo, foi respectivamente 21,7 e $31,1 \%$ maior do que as de Roque et al. (2008) e de Carvalho et al. (2006): 1.809 e de $1.679 \mathrm{~kg} \mathrm{ha}^{-1}$ respectivamente. Por outro lado, em termos nacionais, ficou mais próxima do valor superior, estabelecido pela faixa de 1.000 a $3.000 \mathrm{~kg} \mathrm{ha}^{-1}$, e referido para as condições de feijão irrigado com elevado nível tecnológico (Fahl et al., 1998; Vieira et al., 2006 ); 77,6 e 16,1\%, respectivamente, superior às médias dos Estados de São Paulo (1.239 kg ha-1) e de Goiás (1.895 kg ha-1); e $269,4 \%$ superior à média geral brasileira $\left(817 \mathrm{~kg} \mathrm{ha}^{-1}\right)$ citada pela CONAB (2008) e Martins et al. (2009).

Em todas as camadas trabalhadas, os elevados valores da densidade do solo (DS1 = 1,36 $\mathrm{kg} \mathrm{dm}^{-3}$; DS2 $=1,41 \mathrm{~kg} \mathrm{dm}^{-3} ; \mathrm{DS} 3=1,39 \mathrm{~kg} \mathrm{dm}^{-3}$ ) e da resistência do solo à penetração $(\mathrm{RP} 1=1,56 \mathrm{MPa} ; \mathrm{RP} 2=$ $2,62 \mathrm{MPa} ; \mathrm{RP} 3=3,24 \mathrm{MPa}$ ) atestaram que, durante toda a condução do experimento, o solo encontrava-se compactado. Esse fato tornou-se um fator limitante para máxima expressão da produtividade do feijão, prejudicada tanto pelo deficiente crescimento radicular como pelas consequentes deficiências proporcionadas à absorção nutricional, uma vez que, conforme Vieira et al. (2006), até $87 \%$ de suas raízes situam-se nos primeiros $0,10 \mathrm{~m}$, conferindo-lhe elevada sensibilidade à falta d'água e à compactação. Isso também pode ser explicado pelo fato de que esses valores foram substancialmente superiores aos de um Latossolo Vermelho distroférrico e, ou, eutroférrico, quando em condições naturais e não compactados, referidos para a densidade do solo como $0,98-1,13 \mathrm{~kg} \mathrm{dm}^{-3}$ (Oliveira \& Moniz, 1975), como também de 1,32 MPa, para a resistência à penetração (Carneiro et al., 2009). Assim, a produtividade de grãos de feijão do presente trabalho $\left(2.200,9 \mathrm{~kg} \mathrm{ha}^{-1}\right)$, ainda que obtida nas condições de elevadíssimo nível tecnológico, não atingiu o valor superior da faixa nacional $\left(3.000 \mathrm{~kg} \mathrm{ha}^{-1}\right)($ Fahl et al., 1998; Vieira et al., 2006), devido ao agravado estado de compactação que o solo trabalhado apresentou na sua camada superficial $(0-0,30 \mathrm{~m})$, realçado sobretudo pelos elevados valores de densidade do solo apresentados. Entretanto, potencialmente falando, seu valor poderia ter alcançado $3.390,0 \mathrm{~kg} \mathrm{ha}^{-1}$, conforme estabelecido para o valor máximo desse atributo (Quadro 1). Portanto, nas condições da presente pesquisa, na amplitude de valores observados para a densidade do solo $\left(1,36-1,41 \mathrm{~kg} \mathrm{dm}^{-3}\right)$, esses atributos decisivamente contribuíram com a queda de $26,6 \%$ da produtividade média de grãos de feijão, quando em relação à máxima produtividade nacional (3.000 kg ha-1).

Os valores médios da DS em profundidade indicaram haver maior intensidade de compactação na segunda camada do solo (Quadro 1), onde ocorreu o maior valor $\left(\mathrm{DS} 2=1,41 \mathrm{~kg} \mathrm{dm}^{-3}\right)$. Contudo, em 
relação à $R P$, esses valores foram progressivos em profundidade, indicando ser a terceira camada a mais compactada (RP3 $=3,24 \mathrm{MPa})$. Portanto, esses dois atributos evidenciaram que na faixa entre $0,10 \mathrm{e}$ 0,30 m ocorreu maior compactação no solo trabalhado. Com relação à $\mathrm{DS}$, seus valores médios em profundidade ficaram em consonância com os de Secco et al. (2005) e de Martins et al. (2009), os quais pesquisaram um Latossolo Vermelho distrófico (Rio Grande do Sul) e um distroférrico (Mato Grosso do $\mathrm{Sul}$ ), respectivamente, ambos sob plantio direto.

No que se refere à RP (Quadro 1), seus valores médios em profundidade foram classificados, conforme Arshad et al. (1996), em moderados (RP1) e altos (RP2 e RP3), assim como ficaram em consonância com a magnitude de valores observados por Carvalho et al. (2002) e Carvalho et al. (2006), os quais pesquisaram um Latossolo Vermelho distrófico sul-matogrossense sob preparo convencional e um Latossolo Vermelho distroférrico sul-matogrossense sob plantio direto, respectivamente. Por outro lado, discordaram da magnitude de valores observados por Santos et al. (2005) e Martins et al. (2009), os quais pesquisaram um Latossolo Vermelho distrófico sul-matogrossense sob preparo convencional e um Latossolo Vermelho distroférrico do Mato Grosso do Sul sob plantio direto, respectivamente.

Uma vez que a camada superficial do solo perde mais intensamente água pelo processo de evapotranspiração, os já esperados valores crescentes da umidade gravimétrica (UG) em profundidade ficaram semelhantes aos de Freddi et al. (2005), Santos et al. (2005), Carvalho et al. (2006) e Martins et al. (2009). Dessa forma, conforme Lima et al. (2010), sabe-se que os níveis críticos de resistência à penetração variam com o tipo de solo e com a espécie cultivada. Entretanto, quando a coleta dos dados de $\mathrm{RP}$ é realizada no momento em que a umidade do solo equivaler a dois terços da sua microporosidade (solo friável), trata-se do ponto ideal para fins de trabalhos científicos, visto que a grande maioria deles também é realizada nessas mesmas condições. Assim, como o valor da capacidade de campo do solo trabalhado foi de $0,250 \mathrm{~kg} \mathrm{~kg}^{-1}$, a magnitude da UG $(0,208 ; 0,211$; e $0,214 \mathrm{~kg} \mathrm{~kg}^{-1}$ ) atestou que os dados da RP foram colhidos num ponto ótimo de umidade do solo (Quadro 1).

No quadro 2 , o único atributo do solo a apresentar correlação significativa com a produtividade de grãos de feijão foi a densidade de partículas da camada intermediária estudada. Na figura 1 foi apresentada a equação de regressão entre os referidos atributos, dada pelo seguinte modelo potencial inverso de regressão:

$$
\mathrm{PRG}=4494 . \mathrm{DP} 2^{-0,9047}\left(\mathrm{r}=0,259^{* *}\right)
$$

em que PRG é a produtividade de grãos de feijão (kg ha-1) e DP2 é a densidade de partículas estabelecida na camada entre 0,10 e $0,20 \mathrm{~m}\left(\mathrm{~kg} \mathrm{dm}^{-3}\right)$. Sua correlação, ainda que baixa, foi altamente significativa. Assim, uma vez que o expoente da sua variável dependente foi negativo $(-0,9047)$, a referida regressão, por ser regida pela lei dos decréscimos decrescentes, apresentou a seguinte peculiaridade: a) a variação de $0,01 \mathrm{~kg} \mathrm{dm}^{-3}$ nos menores valores da DP2 $(1,95-$ $1,96 \mathrm{~kg} \mathrm{dm}^{-3}$ ) representou decréscimo de $11,3 \mathrm{~kg} \mathrm{ha}^{-1}$ na produtividade de grãos de feijão (PRG); e b) em contrapartida, nos maiores $\left(2,54-2,55 \mathrm{~kg} \mathrm{dm}^{-3}\right)$, com

Quadro 2. Matriz de correlação linear simples entre a produtividade do feijãoe alguns atributos físicos de um Latossolo Vermelho distroférrico de Selvíria (MS)

\begin{tabular}{|c|c|c|c|c|c|c|c|c|c|c|c|c|}
\hline \multirow{2}{*}{ Atributo $^{(1)}$} & \multicolumn{12}{|c|}{ Coeficientes de correlação( ${ }^{(2)}$} \\
\hline & PRG & DP1 & DP2 & DP3 & DS1 & DS2 & DS3 & RP1 & RP2 & RP3 & UG1 & UG2 \\
\hline DP1 & $-0,076$ & - & - & - & - & - & - & - & - & - & - & - \\
\hline DP2 & $-0,253 * *$ & $0,215 *$ & - & - & - & - & - & - & - & - & - & - \\
\hline DP3 & 0,123 & $-0,099$ & $-0,013$ & - & - & - & - & - & - & - & - & - \\
\hline DS1 & $-0,095$ & 0,139 & $-0,011$ & 0,130 & $\cdot$ & - & - & - & - & - & - & $\cdot$ \\
\hline $\mathrm{DS} 2$ & $-0,086$ & $-0,141$ & $-0,030$ & $-0,140$ & 0,173 & - & - & - & - & - & - & - \\
\hline DS3 & 0,057 & $-0,046$ & $-0,065$ & 0,013 & $-0,032$ & $0,275^{* *}$ & - & - & - & - & - & - \\
\hline $\mathrm{RP} 1$ & $-0,021$ & 0,098 & $-0,137$ & $-0,012$ & 0,160 & $-0,051$ & $-0,020$ & - & - & - & - & - \\
\hline RP2 & $-0,016$ & $-0,045$ & $-0,006$ & $-0,010$ & 0,069 & $0,269 * *$ & 0,051 & $0,477 * *$ & - & - & - & - \\
\hline RP3 & $-0,008$ & $-0,036$ & 0,061 & $-0,100$ & $-0,206^{*}$ & $0,210^{*}$ & 0,112 & 0,152 & $0,279 * *$ & - & - & - \\
\hline UG1 & $-0,117$ & 0,094 & 0,079 & $0,228 *$ & $-0,290 * *$ & $-0,154$ & $-0,030$ & $-0,111$ & $0,271^{* *}$ & $-0,282^{* *}$ & - & - \\
\hline UG2 & 0,088 & 0,029 & $-0,120$ & 0,027 & $-0,010$ & $-0,043$ & $-0,027$ & 0,050 & $-0,124$ & $-0,101$ & $-0,011$ & - \\
\hline UG3 & 0,008 & 0,176 & 0,145 & 0,047 & 0,016 & $-0,068$ & $-0,095$ & $-0,010$ & $-0,221^{*}$ & $-0,092$ & $0,313^{* *}$ & 0,051 \\
\hline
\end{tabular}

(1) PRG é a produtividade de grãos de feijão; DP, DS, RP e UG de 1 a 3, são respectivamente a densidade da partícula, densidade do solo, resistência à penetração e umidade gravimétrica coletadas nas camadas do solo. ${ }^{(2) *}$ e **: Significativos a 5 e $1 \%$, respectivamente. 


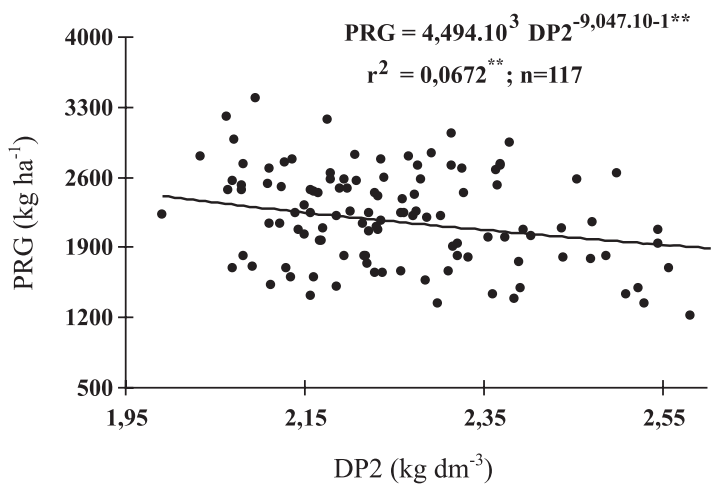

Figura 1. Equação de regressão entre a produtividade do feijão (PRG) e a densidade de partícula (DP2) de um Latossolo Vermelho distroférrico de Selvíria (MS)

base no anterior $\left(11,3 \mathrm{~kg} \mathrm{ha}^{-1}\right)$, o decréscimo foi de $61,1 \%\left(6,9 \mathrm{~kg} \mathrm{ha}^{-1}\right)$. Também, os valores da referida densidade entre 1,95 e $2,20 \mathrm{~kg} \mathrm{dm}^{-3}$ resultaram nas mais elevadas produtividades de feijão (2.200$2.600 \mathrm{~kg} \mathrm{ha}^{-1}$ ). Por outro lado, o aumento do teor de matéria orgânica do solo acarretará diminuição da sua densidade de partículas, conforme preconizado por Carvalho et al. (1999), de forma a proporcionar incremento da produtividade de grãos de feijão. O modelo matemático obtido neste trabalho (Equação 3) ficou de acordo com o de Martins et al. (2009), quando foi pesquisada a correlação, tanto da resistência à penetração como da densidade do solo, com a produtividade de grãos de feijão, também num Latossolo Vermelho distroférrico do Mato Grosso do Sul.

Do ponto de vista das correlações entre os atributos do solo (Quadro 2), aquelas estabelecidas entre UG1 x DS1 $(r=-0,290 * *)$ e DS2 x RP2 $(r=0,269 * *)$ foram significativas e variaram de forma inversa $\mathrm{e}$ direta, respectivamente. Assim, com o aumento da DS1 haverá diminuição da UG1, ficando tal fato de acordo com Martins et al. (2009), bem como sugerindo que nos maiores valores da umidade gravimétrica o solo encontra-se mais compactado. Já com relação à segunda (DS2 x RP2), com o aumento da densidade do solo haverá o mesmo com sua resistência à penetração, estando esse fato de acordo com o observado tanto por Martins et al. (2009) como por Rosa Filho et al. (2009), quando trabalharam também com um Latossolo Vermelho distroférrico do Mato Grosso do Sul.

Os atributos PRG, DS1, RP3, UG1 e UG2 apresentaram dependência espacial entre moderada (DS1; ADE - análise da dependência espacial = 62,3\%) e forte (UG2; $\mathrm{ADE}=93,0 \%$ ) (Quadro 3), cujos modelos de semivariogramas foram do tipo exponencial, esférico e gaussiano. Já aqueles restantes (DP1, DP2, DP3, DS2, DS3, RP1, RP2 e UG3) apresentaram efeito pepita puro. No tocante ao desempenho dos semivariogramas, a relação decrescente deles, analisada pela grandeza do coeficiente de determinação espacial $\left(\mathrm{r}^{2}\right)$, foi a seguinte: (1) UG1 $(0,976),(2) \mathrm{DS} 1$ (0,973), (3) UG2 $(0,962)$, (4) RP3 $(0,925)$ e (5) PRG $(0,766)$. Também, com relação ao avaliador da dependência espacial (ADE), a referida relação foi: (1) UG2 (93,0 \%), (2) RP3 (92,5 \%), (3) PRG (74,1 \%), (4) UG1 (67,2 \%) e (5) DS1 (62,3 \%). Dessa forma, para UG1, DS1, UG2 e RP3 foram constatadas magnitudes elevadas tanto do coeficiente de determinação espacial $\left(\mathrm{r}^{2}\right)$ como do avaliador da dependência espacial (ADE). Por outro lado, o PRG apresentou de forma moderada tanto o coeficiente de determinação espacial $\left(\mathrm{r}^{2}=\right.$ 0,766) como o avaliador da dependência espacial (ADE $=74,1 \%$. Assim, esses dados ficaram basicamente nas mesmas magnitudes de valores que os de Santos et al. (2005) e de Martins et al. (2009), que foram, respectivamente, de $\mathrm{r}^{2}=0,869$ e $\mathrm{ADE}=73,1 \%$ e de $\mathrm{r}^{2}$ $=0,859$ e $\mathrm{ADE}=61,0 \%$.

Em relação aos três primeiros coeficientes de determinação espacial (UG1, DS1 e UG2), a magnitude do primeiro $\left(r^{2}=0,976\right)$ ficou na mesma ordem de grandeza da de Santos et al. (2005), que foi de $r^{2}=0,968$, pesquisado num Latossolo Vermelho distroférrico sul-matogrossense, com o $\mathrm{ADE}=75,5 \%$. $\mathrm{O}$ segundo (DS1) apresentou $\mathrm{r}^{2}$ de 0,973 , ficando na mesma magnitude de valor que o de Martins et al. (2009), pesquisado num Latossolo Vermelho distroférrico sul-matogrossense, que foi de 0,907 e com o $\mathrm{ADE}$ de 86,4 \%. Já para o terceiro, foi de 0,962, concordando também com aquele de Santos et al. (2005), que foi de $\mathrm{r}^{2}=0,946$, com o $\mathrm{ADE}=86,7 \%$ (Quadro 3).

No quadro 3, a relação decrescente dos alcances da dependência espacial foi a seguinte: UG1 (15,5 m), PRG (10,7 m), DS1 (10,5 m), UG2 (9,4 m) e RP3 $(8,6 \mathrm{~m})$. Em relação ao primeiro (UG1), o alcance obtido no presente foi inferior aos de Roque et al. (2008) e de Santos et al. (2005), que foram de 24,3 e de 25,9 m, respectivamente. Para o segundo (PRG), foi menor que o de Martins et al. (2009) e o de Carvalho et al. (2006), que foram respectivamente de 17,8 e de 20,2 m, assim como superior ao de Santos et al. (2005) e de Roque et al. (2008): 6,1 e 9,2 m, respectivamente. No terceiro (DS1), foi inferior ao de Martins et al. (2009), que foi de 29,9 m. Para o quarto (UG2), foi inferior aos de Santos et al. (2005) e de Martins et al. (2009), que foram respectivamente de 11,8 e de $36,3 \mathrm{~m}$. Para o último (RP3), foi inferior aos de Carvalho et al. (2006) e de Santos et al. (2005), que foram respectivamente de 64,5 e de $16,1 \mathrm{~m}$. Portanto, exclusivamente com base na presente pesquisa, assim como visando auxiliar a pesquisa futura, na qual os mesmos atributos estejam envolvidos, os valores dos alcances da dependência espacial a serem utilizados nos pacotes geoestatísticos, que alimentarão os pacotes computacionais empregados na agricultura de precisão, no geral, não deverão ser menores do que $8,6 \mathrm{~m}$ para os atributos do solo. Por outro lado, exclusivamente para o atributo da planta, não menores do que $10,7 \mathrm{~m}$. 
Quadro 3. Parâmetros dos semivariogramas simples e cruzado ajustados para a produtividade do feijão e de alguns atributos físicos de um Latossolo Vermelho distroférrico de Selvíria (MS)

\begin{tabular}{|c|c|c|c|c|c|c|c|c|}
\hline \multirow{3}{*}{ Atributo $^{(1)}$} & \multicolumn{8}{|c|}{ Parâmetros } \\
\hline & \multirow{2}{*}{ Modelo $^{(2)}$} & \multirow{2}{*}{$\begin{array}{l}\text { Efeito pepita } \\
\qquad\left(\mathrm{C}_{0}\right)\end{array}$} & \multirow{2}{*}{$\begin{array}{c}\text { Patamar } \\
\left(C_{0}+C\right)\end{array}$} & \multirow{2}{*}{$\begin{array}{c}\text { Alcance }(\mathrm{m}) \\
\left(\mathrm{A}_{0}\right)\end{array}$} & \multirow{2}{*}{$\mathbf{R}^{2}$} & \multirow[t]{2}{*}{$\mathbf{S Q R}^{(3)}$} & \multicolumn{2}{|c|}{$\begin{array}{c}\text { Avaliador da } \\
\text { dependência espacial }\end{array}$} \\
\hline & & & & & & & $\mathrm{ADE}^{(4)}$ & Classe \\
\hline \multicolumn{9}{|c|}{$\gamma(\mathrm{h})$ simples do atributo da planta } \\
\hline PRG (kg ha $\left.{ }^{-1}\right)$ & $\exp (54)$ & $4,650.10^{4}$ & $1,794.10^{5}$ & 10,7 & 0,766 & $1,220.10^{9}$ & 74,1 & moderada \\
\hline \multicolumn{9}{|c|}{$\gamma(\mathrm{h})$ simples do atributo do solo } \\
\hline $\mathrm{DP} 1\left(\mathrm{~kg} \mathrm{dm}^{-3}\right)$ & epp & $1,717.10^{-2}$ & $1,717.10^{-2}$ & - & - & - & - & - \\
\hline $\mathrm{DP} 2\left(\mathrm{~kg} \mathrm{dm}^{-3}\right)$ & epp & $2,124 \cdot 10^{-2}$ & $2,124 \cdot 10^{-2}$ & - & - & - & - & - \\
\hline DP3 $\left(\mathrm{kg} \mathrm{dm}^{-3}\right)$ & epp & $1,743.10^{-2}$ & $1,743.10^{-2}$ & - & - & - & - & - \\
\hline $\operatorname{DS} 1\left(\mathrm{~kg} \mathrm{dm}^{-3}\right)$ & gau (69) & $4,000.10^{-3}$ & $1,060.10^{-2}$ & 10,5 & 0,973 & $8,660.10^{-7}$ & 62,3 & moderada \\
\hline $\mathrm{DS} 2\left(\mathrm{~kg} \mathrm{dm}^{-3}\right)$ & epp & $4,555.10^{-3}$ & $4,555.10^{-3}$ & - & - & - & - & - \\
\hline DS3 $\left(\mathrm{kg} \mathrm{dm}^{-3}\right)$ & epp & $3,221.10^{-3}$ & $3,221.10^{-3}$ & - & - & - & - & - \\
\hline RP1 (MPa) & epp & $5,298.10^{-1}$ & $5,298.10^{-1}$ & - & - & - & - & - \\
\hline RP2 (MPa) & epp & $4,971.10^{-1}$ & $4,971 \cdot 10^{-1}$ & - & - & - & - & - \\
\hline RP3 (MPa) & esf (51) & $1,135.10^{-1}$ & $3,860.10^{-1}$ & 8,6 & 0,925 & $3,583.10^{-3}$ & 92,5 & forte \\
\hline UG1 $\left(\mathrm{kg} \mathrm{kg}^{-1}\right)$ & $\exp (62)$ & $2,260.10^{-4}$ & $6,890 \cdot 10^{-4}$ & 15,5 & 0,976 & $1,764.10^{-9}$ & 67,2 & moderada \\
\hline $\mathrm{UG} 2\left(\mathrm{~kg} \mathrm{~kg}^{-1}\right)$ & $\exp (65)$ & $3,700.10^{-5}$ & $5,230.10^{-4}$ & 9,4 & 0,962 & $2,009.10^{-9}$ & 93,0 & forte \\
\hline UG3 $\left(\mathrm{kg} \mathrm{kg}^{-1}\right)$ & epp & $8,620.10^{-4}$ & $8,620.10^{-4}$ & - & - & - & - & - \\
\hline \multicolumn{9}{|c|}{$\gamma(\mathrm{h})$ cruzado entre atributo da planta e do solo } \\
\hline $\mathrm{PRG}=\mathrm{f}(\mathrm{UG} 2)$ & esf (35) & $6,940.10^{-1}$ & 1,808 & 31,1 & 0,635 & $7,350.10^{-1}$ & 61,6 & moderada \\
\hline
\end{tabular}

(1) PRG: produtividade de grãos do feijão, DP: densidade da partícula, DS: densidade do solo, RP: resistência à penetração, UG: umidade gravimétrica; exp: exponencial, gau: gausiano, esf: esférico; e epp: efeito pepita puro; modelo sucedido por número entre parêntesis, significando o número de pares no primeiro lag; SQR: soma dos quadrados dos resíduos; ADE: avaliador da dependência espacial.

Na comparação inicial dos mapas de krigagem simples dos atributos do solo (DS1, RP3, UG1 e UG2) com aquele da produtividade de grãos de feijão (PRG), cujos parâmetros dos semivariogramas encontramse no quadro 3 , foi verificada elevada semelhança espacial direta entre a UG2 e a PRG. Dessa forma, na figura $2 \mathrm{e}$,f pode-se constatar que nos sítios onde ocorreram as maiores e, ou, menores UG2s houve o mesmo com a PRG. Entretanto, para o restante dos atributos do solo (DS1, RP3 e UG1) esse fato não ocorreu. Seguidamente, objetivando atestar a interrelação espacial da produtividade de grãos de feijão com os atributos do solo, verificou-se que apenas a UG2 resultou cokrigagem com a PRG [PRG $=\mathrm{f}(\mathrm{UG} 2)]$, apresentando coeficiente de determinação espacial $\left(\mathrm{r}^{2}\right)$ de 0,635 , equivalente à dependência espacial (ADE) de $61,6 \%$ (Quadro 3, Figura 3). Portanto, com a cifra de $61,6 \%$, nos sítios, onde a UG2 alcançou seus menores valores $\left(0,160-0,194 \mathrm{~kg} \mathrm{~kg}^{-1}\right.$; Figura 2f) ocorreu o mesmo com a PRG (1.487-1.992 $\mathrm{kg} \mathrm{ha}^{-1}$; Figura 2e; Figura 3c). Já naqueles maiores $(0,205-$ $0,239 \mathrm{~kg} \mathrm{~kg}^{-1}$; Figura 2f) a PRG foi de 2.160 $2.665 \mathrm{~kg} \mathrm{ha}^{-1}$ (Figura 2e; Figura 3c).

A apreciável cokrigagem atestada no presente trabalho (Quadro 3; Figura 3) ficou em consonância com a de Martins et al. (2009), que também pesquisaram a inter-relação espacial da produtividade de grãos de feijão com atributos físicos de um Latossolo Vermelho distroférrico sul-matogrossense. Esses autores encontraram as oito seguintes cokrigagens: $P R G=f(D S 1), P R G=f(D S 3), P R G=f(U G 3), P R G=$ $\mathrm{f}(\mathrm{UV} 1), \mathrm{PRG}=\mathrm{f}(\mathrm{UV} 2), \mathrm{PRG}=\mathrm{f}(\mathrm{UV} 3), \mathrm{PRG}=\mathrm{f}(\mathrm{RP} 1) \mathrm{e}$ $\mathrm{PRG}=\mathrm{f}(\mathrm{RP} 4)$, cujos coeficientes de determinação espacial $\left(\mathrm{r}^{2}\right)$ variaram entre 0,105 e 0,734 , equivalentes à variação da dependência espacial (ADE): entre 96,1 e 99,9\%. Contudo, há que se ressaltar que a variação espacial da PRG em função da UG3, observada por eles, foi inversa, o que contrariou a cokrigagem do presente trabalho $[\mathrm{PRG}=\mathrm{f}(\mathrm{UG} 2)]$, que foi direta.

A correlação linear atestada entre PRG e DP2 (Figura 1; Equação 3), assim como a apreciável cokrigagem entre PRG e UG2 (Quadro 3, Figura 3), sugerem que tais atributos do solo (DP2 e UG2) são bons indicadores da sua qualidade física quando o objetivo for o de implementar a produtividade de grãos de feijão. Assim, podem ser recomendadas específicas práticas conservacionistas do solo, dirigidas aos sítios onde a UG2 resultou seus menores valores, visando elevar a respectiva produtividade de grãos de feijão local. 

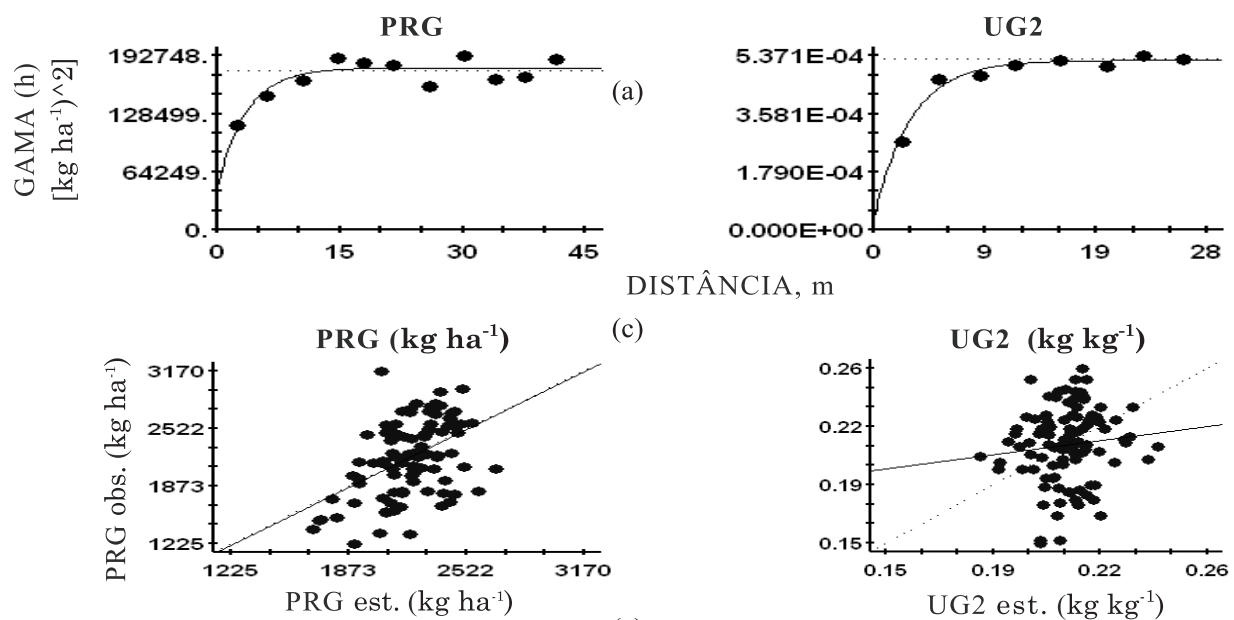

(c)

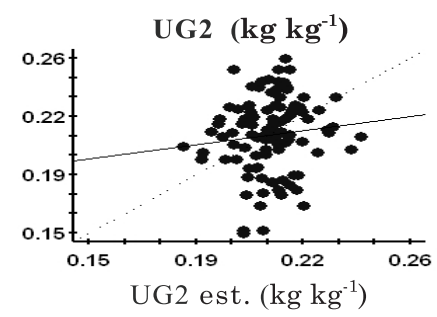

(d)

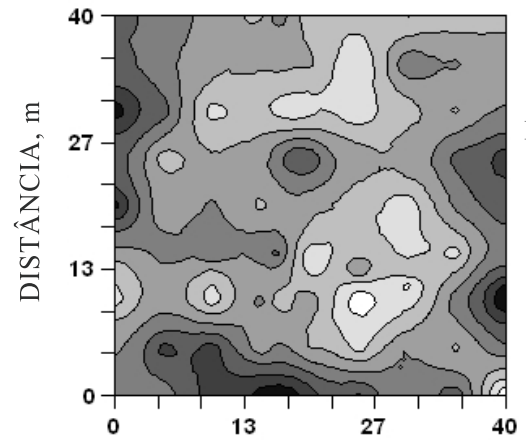

(e)

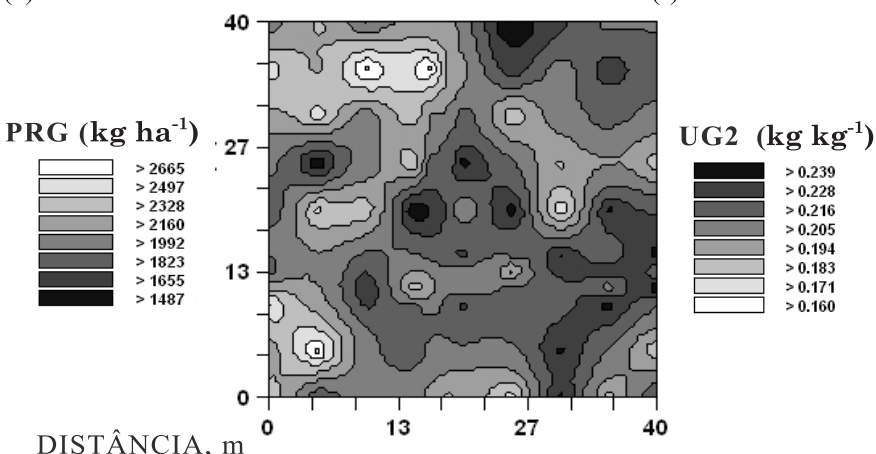

Figura 2. Componentes geoestatísticos da produtividade do feijão (PRG) e da umidade gravimétrica (UG2) de um Latossolo Vermelho distroférrico de Selvíria (MS).
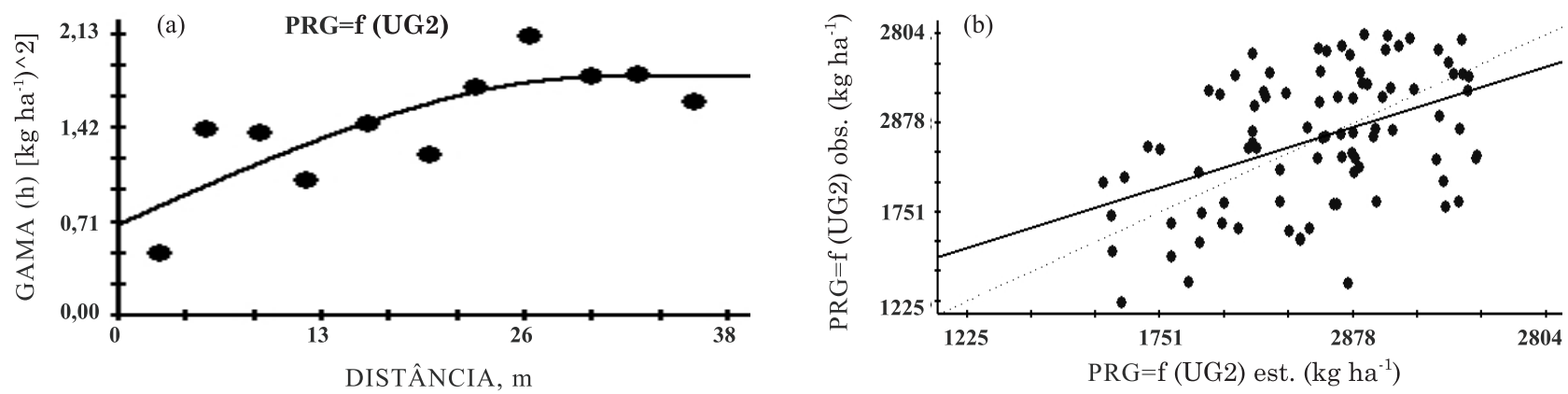

(c) $\quad$ PRG $=$ f (UG2)

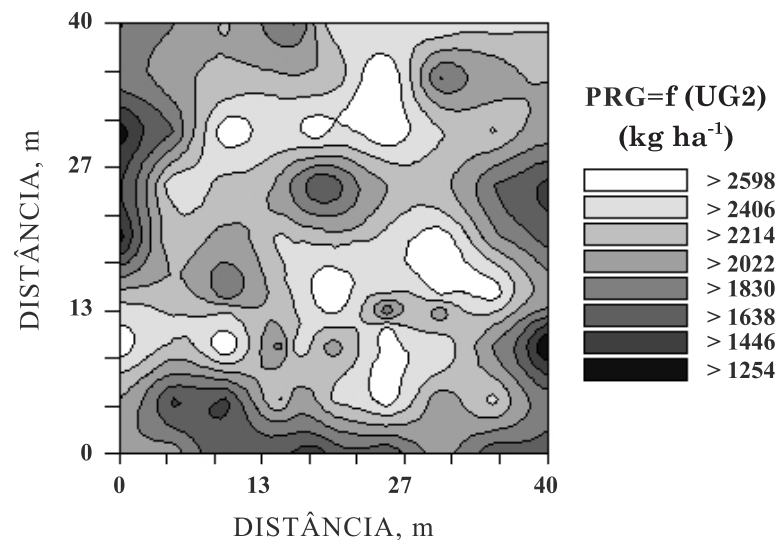

Figura 3. Componentes geoestatísticos da produtividade do feijão em função da UG2 de um Latossolo Vermelho distroférrico de Selvíria (MS). 


\section{CONCLUSÕES}

1. Nas condições de elevado nível tecnológico de manejo do solo, a produtividade média de grãos de feijão não atingiu seus maiores valores. Isso porque o estado de compactação presente no solo sob o sistema plantio direto provavelmente desencadeou redução de $26,6 \%$ nessa produtividade.

2. Os valores médios da densidade do solo de 1,36 $1,41 \mathrm{~kg} \mathrm{dm}^{-3}$ proporcionaram substancial queda da produtividade de grãos de feijão.

3. Do ponto de vista linear, a produtividade de grãos de feijão foi explicada por um modelo potencial inverso altamente significativo, dado em função da densidade de partícula do solo.

4. Do ponto de vista espacial, a produtividade de grãos de feijão pôde ser estimada por meio da cokrigagem direta com a umidade gravimétrica do solo. Assim, valores superiores a $0,205 \mathrm{~kg} \mathrm{~kg}^{-1}$ desse atributo do solo indicaram sítios com as mais elevadas produtividades.

\section{LITERATURA CITADA}

ARSHAD, M.A.; LOWERY, B. \& GROSSMAN, B. Physical tests for monitoring soil quality. In: DORAN, J.W. \& JONES, A.J., eds. Methods for assessing soil quality. Madison, Soil Science Society America, 1996. p.123-141 (SSSA Special Publication, 49)

BENGOUGH, A.G.; CAMPBELL, D.J. \& O' SULLIVAN, M.F. Penetrometer techniques in relation to soil compaction and root growth. In: SMITH, K.A. \& MULLINS, C.E., eds. Soil and environmental analysis: Physical methods. 2.ed. New York, Marcel Dekker, 2001. p.377-403.

BERTONI, J. \& LOMBARDI NETO, F. Conservação do solo. São Paulo, Ícone, 1990. 355p.

CAMARGO, O.A. \& ALLEONI, L.R.F. Compactação do solo e desenvolvimento das plantas. Piracicaba, Escola Superior de Agricultura Luiz de Queiróz, 1997. 132p.

CARNEIRO, M.A.C.; SOUZA, E.D.; REIS, E.F.; PEREIRA, H.S. \& AZEVEDO, W.R. Atributos físicos, químicos e biológicos de solo de cerrado sob diferentes sistemas de uso e manejo. R. Bras. Ci. Solo, 33:147-157, 2009.

CARVALHO, E.J.M.; FIGUEIREDO, M.S. \& COSTA, L.M. Comportamento físico-hídrico de um podzólico vermelhoamarelo câmbico fase terraço sob diferentes sistemas de manejo. Pesq. Agropec. Bras., 34:257-265, 1999.

CARVALHO, M.P.; SORATTO, R.P. \& FREDDI, O.S. Variabilidade espacial de atributos físicos em um Latossolo Vermelho distrófico sob preparo convencional em Selvíria, estado de Mato Grosso do Sul. Acta Sci. Agron., 24:13531361, 2002.

CARVALHO, G.J.; CARVALHO, M.P.; FREDDI, O.S. \& MARTINS, M.V. Correlação da produtividade do feijão com a resistência à penetração do solo sob plantio direto. R. Bras. Eng. Agric. Amb., 10:765-771, 2006.
COELHO, A.M. Agricultura de precisão: Manejo da variabilidade espacial e temporal dos solos e da cultura. In: CURI, N.; MARQUES, J.J.; GUILHERME, L.R.G.; LIMA, J.M.; LOPES, A.S. \& ALVAREZ V., V.H., eds. Tópicos em ciência do solo. Viçosa, MG, Sociedade Brasileira de Ciência do Solo, 2003. v.3. p.249-290.

COMPANHIA NACIONAL DE ABASTECIMENTO - CONAB. Feijão total (1 $1^{\mathrm{a}}, 2^{\mathrm{a}}$ e $3^{\mathrm{a}}$ Safra). Quadro Comparativo de Área, Produção e Produtividade, Safras 2006/2007 e 2007/ 2008 - $8^{\circ}$ Levantamento. maio 2008. Disponível em: <http:/ /www.conab.gov.br/conabweb>.

EGUCHI, E.S.; SILVA, E.L. \& OLIVEIRA, M.S. Variabilidade espacial da textura e da densidade de partículas em um solo aluvial no município de Lavras, MG. R. Bras. Eng. Agric. Amb., 6:242-246, 2002.

EMPRESA BRASILEIRA DE PESQUISA AGROPECUÁRIA EMBRAPA. Manual de métodos de análise do solo. 2.ed. Rio de Janeiro, 1997.

EMPRESA BRASILEIRA DE PESQUISA AGROPECUÁRIA EMBRAPA. Sistema brasileiro de classificação de solos. 2.ed. Rio de Janeiro, 2006. 306p.

FAHL, J.I.; CAMARGO, M.B.P.; PIZZINATO, M.A.; BETTI, J.A.; MELO, A.M.T.; DeMARIA, I.C. \& CANGIANI, A.M., eds. Instruções agrícolas para as principais culturas econômicas.. 6.ed. Campinas, Instituto Agronômico de Campinas, 1998. 396p. (Boletim, 200)

FREDDI, O.S.; CARVALHO, M.P.; CENTURION, J.F. \& BARBOSA, G.F. Variabilidade espacial da produtividade do feijão em um Latossolo Vermelho distroférrico sob preparo convencional e plantio direto. Acta Sci. Agron., 27:61-67, 2005 .

FREDDI, O.S.; CARVALHO, M.P.; VERONESI JÚNIOR, V. \& CARVALHO, G.J. Produtividade do milho relacionada com a resistência mecânica à penetração do solo sob preparo convencional. Eng. Agríc., 26:113-121, 2006.

GS+: Geostatistics for environmental sciences. 7.ed. Plainwell, Gamma Desing Software, 2004. 159p.

INSTITUTO AGRONÔMICO DO PARANÁ - IAPAR. Plantio direto no Estado do Paraná. Londrina, 1981. 244p. (Boletim Técnico, 23)

KITAMURA, A.E.; CARVALHO, M.P. \& LIMA, C.G.R. Relação entre a variabilidade espacial das frações granulométricas do solo e a produtividade do feijoeiro sob plantio direto. R. Bras. Ci. Solo, 31:361-379, 2007.

LIMA, C.G.R.; CARVALHO, M.P.; MELLO, L.M.M. \& LIMA, R.C. Correlação linear e espacial entre a produtividade de forragem, a porosidade total e densidade do solo de Pereira Barreto (SP). R. Bras. Ci. Solo, 31:1233-1244, 2007.

LIMA, C.G.R.; CARVALHO, M.P.; NARIMATSU, K.C.P.; SILVA, M.M. \& QUEIROZ, H.A. Atributos físico-químicos de um Latossolo do Cerrado Brasileiro e sua relação com características dendrométricas do eucalipto. R. Bras. Ci. Solo, 34:163-173, 2010.

MARTINS, M.V.; CARVALHO, M.P.; ANDREOTTI, M. \& MONTANARI, R. Correlação linear e espacial entre a produtividade do feijoeiro e atributos físicos de um Latossolo Vermelho distroférrico de Selvíria, Estado de Mato Grosso do Sul. Acta Sci. Agron., 31:147-154, 2009. 
OLIVEIRA, J.B. \& MONIZ, A.C. Levantamento pedológico detalhado da estação experimental de Ribeirão Preto, SP. Bragantia, 34:59-114, 1975.

ROQUE, M.W.; MATSURA, E.E.; SOUZA, Z.M.; BIZARI, D.R. \& SOUZA, A.L. Correlação linear e espacial entre a resistência do solo ao penetrômetro e a produtividade do feijoeiro irrigado. R. Bras. Ci. Solo, 32:1827-1835, 2008.

ROSA FILHO, G.; CARVALHO, M.P.; ANDREOTTI, M.; MONTANARI, R.; BINOTTI, F.F.S. \& GIOIA, M.T. Variabilidade da produtividade da soja em função de atributos físicos de um Latossolo Vermelho distroférrico sob plantio direto. R. Bras. Ci. Solo, 33:287-295, 2009.

SANTOS, P.A.; CARVALHO, M.P.; FREDDI, O.S.; KITAMURA, A.E.; FREITAS, E.E. \& VANZELA, L.S. Correlação linear e espacial entre o rendimento de grãos do feijoeiro e a resistência mecânica à penetração em um Latossolo Vermelho distroférrico. R. Bras. Ci. Solo, 29:287-295, 2005.

SANTOS, M.L.; CARVALHO, M.P.; RAPASSI, R.M.A.; MURAISHI, C.T.; MALLER, A. \& MATOS, F.A. Correlação linear e espacial entre produtividade de milho (Zea mays L.) e atributos físicos de um Latossolo Vermelho distroférrico sob plantio direto do Cerrado Brasileiro. Acta Sci. Agron., 28:313-321, 2006.
SECCO, D.; DA ROS, C.O.; SECCO, J.K. \& FIORIN, J.E. Atributos físicos e produtividade de culturas em um Latossolo Vermelho argiloso sob diferentes sistemas de manejo. R. Bras. Ci. Solo, 29:407-414, 2005.

SCHLOTZHAVER, S.D. \& LITTELL, R.C. SAS System for elementary statistical analysis. 2.ed. Cary, 1997. 905p.

SOUZA, Z.M.; SILVA, M.L.S.; GUIMARÃES, G.L.; CAMPOS, D.T.S.; CARVALHO, M.P. \& PEREIRA, G.T. Variabilidade espacial de atributos físicos em um Latossolo Vermelho distrófico sob semeadura direta em Selvíria (MS). R. Bras. Ci. Solo, 25:699-707, 2001.

SOUZA, Z.M.; CAMPOS, M.C.C.; CALVACANTE, I.H.L.; MARQUES JÚNIOR, J.; CESARIN, L.G. \& SOUZA, S.R. Dependência espacial da resistência do solo à penetração e do teor de água do solo sob cultivo contínuo de cana-deaçúcar. Ci. Rural, 36:128-134, 2006.

TRANGMAR, B.B.; YOST, R.S. \& UEHARA, G. Application of geostatistics to spatial studies of soil properties. Adv. Agron., 38:45-94, 1985.

VIEIRA, C.; PAULA JÚNIOR, T.J. \& BORÉM, A. Feijão: Aspectos gerais e cultura no Estado de Minas. 2.ed. Viçosa, MG, Universidade Federal de Viçosa, 2006. 600p. 